\title{
Pengaruh Financial Behavior, Risk Tolerance, Dan Financial Strain Terhadap Financial Satisfaction
}

\author{
Meitasari Sherlyani dan Ary Satria Pamungkas \\ Program Studi Manajemen Fakultas Ekonomi Universitas Tarumanagara, Jakarta \\ Email: meitasherly18@gmail.com
}

\begin{abstract}
The purpose of this research is to analyze the influence of Financial Behavior, Risk Tolerance and Financial Strain toward Financial Satisfaction. The subjects of this research are doctors in Jakarta. Sample was selected using convenience sampling method amounted to 150 respondents through spreading questionnaire online and going to doctor's clinics. Data processing techniques using structural equation modeling what helped by SmartPLS.3.2.7 program. The result of this study reveals that Financial Behavior and Financial Strain do not have effects toward Financial Satisfaction, meanwhile Risk Tolerance have effects toward Financial Satisfaction.
\end{abstract}

Keywords: Financial Behavior, Risk Tolerance, Financial Strain, Financial Satisfaction

\begin{abstract}
Abstrak: Tujuan dari penelitian ini adalah untuk menguji pengaruh Financial Behavior, Risk Tolerance dan Financial Strain terhadap Financial satisfaction. Sampel pada penelitian ini adalah profesi dokter di Jakarta. Sampel dipilih dengan metode convenience sampling yang berjumlah 150 responden dengan menyebarkan kuesioner online dan menyebarkan kuesioner ke klinik-klinik praktik. Teknik analisis data yang digunakan adalah structural equation modeling yang dibantu dengan bantuan program SmartPLS.3.2.7. Hasil yang didapat pada penelitian ini menunjukkan bahwa tidak terdapat pengaruh Financial Behavior dan Financial Strain terhadap Financial Satisfaction, dan terdapat pengaruh Risk Tolerance terhadap Financial Satisfaction.
\end{abstract}

Kata kunci: Financial Behavior, Risk Tolerance, Financial Strain, Financial Satisfaction

\section{Latar Belakang}

Aristoteles dalam Seligman (2002:27) mengemukakan bahwa segala perilaku individu dilakukan untuk membuat dirinya bahagia. Veenhoven (2011) mengatakan bahwa kebahagiaan dapat disebut juga sebagai kepuasan hidup. Kepuasan hidup sendiri erat kaitannya dengan kesejahteraan karena pada akhirnya seseorang akan bahagia dan mencapai kepuasan hidup jika ia merasa dirinya sudah sejahtera.

Dalam Peraturan Pemerintah nomor 30 Tahun 2012 disebutkan bahwa kesejahteraan sosial merupakan kondisi dimana individu sebagai warga negara dapat memenuhi kebutuhan material, spiritual, dan sosialnya agar dapat hidup dengan kehidupan yang layak serta mampu untuk mengembangkan diri sehingga individu dapat melaksanakan fungsi sosialnya. Jika ditinjau dari sudut pandang keuangan, kesejahteraan individu didapatkan jika telah mencapai yang disebut kepuasan finansial (financial satisfaction). Menurut George (1992) 
financial satisfaction selama ini telah dijadikan sebagai model untuk mengukur kepuasan hidup (life satisfaction) dan ukuran lainnya atas kesejahteraan secara subjektif.

Terdapat beberapa faktor yang mempengaruhi financial satisfaction seseorang, diantaranya adalah financial behavior, financial strain dan risk tolerance.

\section{KAJIAN TEORI}

Menurut Altsani, Hasibuan, dan Lubis (2017), "Financial satisfaction is the satisfaction of a person toward a personal financial. The person who has financial satisfaction is the one who satisfy with the recent financial condition. Furthermore, the financial satisfaction as subjective's perception that sufficient for the financial resources". Definisi dari financial satisfaction tersebut dapat diartikan bahwa Financial satisfaction adalah kepuasan individu terhadap keadaan finansialnya. Individu yang memiliki financial satisfaction adalah mereka yang puas dengan keadaan finansialnya sekarang ini. Oleh karena itu, financial satisfaction adalah perspektif subjektif yang cukup untuk sumber daya keuangan.

Menurut Joo dan Grable (2004), "financial behavior can be explained by several factors. The first individual's behavior himself. The attitude and behavior of someone in financial field is called financial behavior". Dapat diartikan bahwa Financial behavior bisa dijelaskan melalui beberapa faktor. Pertama adalah adalah perilaku individu itu sendiri. Sikap dan perilaku dari individu di dalam bidang keuangan disebut juga financial behavior.

Menurut McKenzie dan Hallahan (2004), "Risk tolerance is a person attitude's towards accepting risk, it is important concept that has implication for both financial service provider and concumer" dari definisi tersebut dapat diartikan bahwa risk tolerance adalah sikap seseorang dalam menerima risiko dan merupakan konsep yang penting yang mempunyai implikasi dalam layanan keuangan dan konsumen.

Menurut Asebedo dan Wilmarth (2017) "Financial strain is perceived economic pressure that creates a potentially harmful, threatening, or challenging situation aligns with the definition of a stressor to which individual choose their emotional response". Dari pernyataan tersebut dapat diartikan bahwa financial strain adalah tekanan ekonomi yang dapat menimbulkan situasi yang berbahaya, mengancam atau menantang sama seperti pengertian dari stressor (tekanan) yang dipilih oleh individu atas respon emosionalnya.

\section{Kaitan antar Variabel}

Penelitian Coskuner (2016) menunjukan hasil adanya pengaruh yang signifikan antara financial behavior dan financial satisfaction meskipun financial behavior merupakan variabel yang paling sedikit menunjukan pengaruh yang signifikan dengan financial satisfaction diantara variabel lainnya. Menurut penelitian, financial satisfaction individu akan menunjukan sedikit peningkatan saat individu mengadopsi financial behavior yang positif.

Menurut penelitian yang dilakukan oleh Jeong dan Hanna (2004), terdapat pengaruh yang positif antara risk tolerance dan financial satisfaction. Dalam penelitiannya, Jeong dan Hanna (2004) menyebutkan bahwa semakin besar risk tolerance yang dimiliki individu, maka semakin besar pula tingkat kepuasannya terhadap keadaan finansialnya (financial satisfaction). 
Penelitian yang dilakukan oleh Falahati, Sabri, dan Paim (2012) juga menunjukan bahwa terdapat pengaruh yang signifikan financial strain terhadap financial satisfaction. Hasil penelitian tersebut menunjukan bahwa financial satisfaction individu akan menurun dengan adanya financial strain dan begitu pula sebaliknya. Penelitian tersebut juga menunjukan financial literacy yang baik akan berdampak pada financial behavior yang baik pula sehingga mengurangi tingkat financial strain yang akan berakibat pada tingkat financial satisfaction yang lebih tinggi

\section{METODOLOGI}

Populasi pada penelitian ini adalah dokter yang berada di wilayah DKI Jakarta. Teknik yang dipakai dalam pemilihan sampel penelitian ini adalah dengan teknik convenience sampling dan didapatkan adalah sebanyak 150 responden. Pengumpulan sampel dibanru dengan bantuan google form yang disebar secara online dan penyebaran kuesioner secara manual ke klinik-klinik. Teknik analisis data yang digunakan adalah structural equation modeling yang dibantu dengan bantuan program SmartPLS 3.2.7. Suatu model penelitian harus memenuhi syarat valid dan reliabel, sehingga pada penelitian ini model akan diuji validitas dan reliabilitasnya. Setelah sebuah model penelitian memenuhi pesyaratan uji model pengukuran (outer model analysis) maka tahap selanjutnya adalah melakukan analisis model struktural (inner model analysis) penelitian kriteria-kriteria yang harus dipenuhi dalam analisis model struktural meliputi nilai koefisien determinasi (R2), predictive relevance $(\mathrm{Q} 2)$, effect size (f2) dan path coefficients.

Pada penelitian yang menggunakan PLS-SEM, maka pengujian hipotesis dilakukan dengan melihat nilai t-statistik dari sampel independent.

\section{Hasil Uji Statistik}

Validitas dan Reliabilitas. Uji validitas pada penelitian ini dengan melihat nilai convergent validity dan discriminant validity. Convergent validity adalah sejauh mana indikator dalam konstruk yang sama berkorelasi secara positif. Convergent validity dapat dilakukan dengan menghitung nilai outer loading factor setiap indikator dan nilai average variance extracted (AVE). Tabel 1. menunjukkan nilai AVE masing-masing variabel yang lebih besar dari 0,5 yang artinya memenuhi salah satu kriteria dari convergent validity

Tabel 1. Hasil analisis Average Variance Extracted (AVE)

\begin{tabular}{|l|c|}
\hline & Average Variance Extracted (AVE) \\
\hline Financial Behavior & 0.552 \\
\hline Financial Satisfaction & 0.619 \\
\hline Financial Strain & 0.734 \\
\hline Risk Tolerance & 0.521 \\
\hline
\end{tabular}

Tabel 2. Hasil Nilai Loading Factor

\begin{tabular}{|l|l|l|l|l|}
\hline & Financial & Risk & Financial & Financial \\
& Behavior & Tolerance & Strain & Satisfaction \\
\hline
\end{tabular}


Sherlyani dan Pamungkas: Pengaruh Financial Behavior...

\begin{tabular}{|l|l|l|l|l|}
\hline FB1 & 0.684 & & & \\
\hline FB2 & 0.824 & & & \\
\hline FB3 & 0.756 & & & \\
\hline FB4 & 0.730 & & & \\
\hline FB5 & 0.711 & & & \\
\hline RT1 & & 0.647 & & \\
\hline RT2 & & 0.609 & & \\
\hline RT3 & & 0.736 & & \\
\hline RT4 & & 0.786 & & \\
\hline RT5 & & 0.746 & & \\
\hline RT6 & & 0.788 & & \\
\hline FSN1 & & & 0.815 & \\
\hline FSN2 & & & 0.826 & \\
\hline FSN3 & & & 0.838 & \\
\hline FSN4 & & & 0.877 & \\
\hline FSN5 & & & 0.922 & \\
\hline FS1 & & & & 0.776 \\
\hline FS2 & & & & 0.757 \\
\hline FS3 & & & & 0.778 \\
\hline FS4 & & & & 0.824 \\
\hline FS5 & & & & 0.792 \\
\hline FS6 & & & & 0.792 \\
\hline
\end{tabular}

Gambar 1. Hasil convergent Validity 


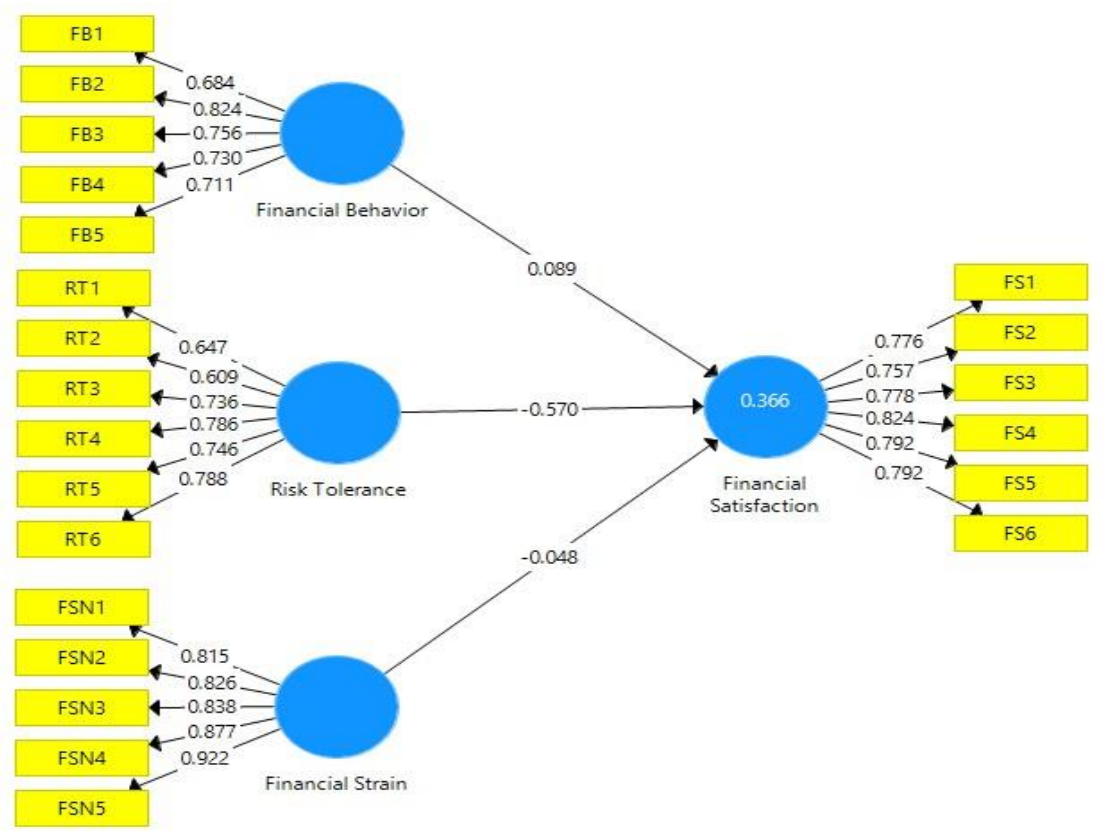

Suatu instrumen dianggap valid dengan metode Fornell-Larcker, apabila nilai akar kuadrat AVE dari masing-masing konstruk lebih besar daripada korelasi dengan variabel laten lainnya. Demikian pula dengan pendekatan nilai cross loadings. Nilai loadings masingmasing indikator dari suatu konstruk harus lebih tinggi daripada nilai cross loadings indikator tersebut dalam konstruk lainnya. Berikut Tabel 3. yang menunjukkan hasil nilai cross loadings dari setiap indikator.

Tabel 3. Hasil nilai Cross Loading

\begin{tabular}{|l|l|l|l|l|}
\hline & $\begin{array}{l}\text { Financial } \\
\text { Behavior }\end{array}$ & $\begin{array}{l}\text { Risk } \\
\text { Tolerance }\end{array}$ & $\begin{array}{l}\text { Financial } \\
\text { Strain }\end{array}$ & $\begin{array}{l}\text { Financial } \\
\text { Satisfaction }\end{array}$ \\
\hline FB1 & 0.684 & -0.038 & -0.028 & 0.051 \\
\hline FB2 & 0.824 & -0.136 & -0.192 & 0.182 \\
\hline FB3 & 0.756 & -0.077 & -0.014 & 0.095 \\
\hline FB4 & 0.730 & -0.039 & -0.035 & 0.109 \\
\hline FB5 & 0.711 & -0.175 & -0.185 & 0.151 \\
\hline RT1 & -0.073 & 0.647 & 0.251 & -0.311 \\
\hline RT2 & -0.004 & 0.609 & 0.249 & -0.330 \\
\hline RT3 & -0.053 & 0.736 & 0.252 & -0.376 \\
\hline RT4 & -0.213 & 0.786 & 0.167 & -0.560 \\
\hline RT5 & -0.075 & 0.746 & 0.083 & -0.465 \\
\hline
\end{tabular}




\begin{tabular}{|l|l|l|l|l|}
\hline RT6 & -0.149 & 0.788 & 0.222 & -0.463 \\
\hline FSN1 & -0.091 & 0.167 & 0.815 & -0.051 \\
\hline FSN2 & -0.070 & 0.159 & 0.826 & -0.015 \\
\hline FSN3 & -0.126 & 0.259 & 0.838 & -0.160 \\
\hline FSN4 & -0.080 & 0.194 & 0.877 & -0.213 \\
\hline FSN5 & -0.170 & 0.277 & 0.922 & -0.223 \\
\hline FS1 & 0.170 & -0.479 & -0.240 & 0.776 \\
\hline FS2 & 0.160 & -0.457 & -0.231 & 0.757 \\
\hline FS3 & 0.117 & -0.368 & -0.189 & 0.778 \\
\hline FS4 & 0.147 & -0.486 & -0.181 & 0.824 \\
\hline FS5 & 0.121 & -0.478 & -0.105 & 0.792 \\
\hline FS6 & 0.126 & -0.520 & -0.069 & 0.792 \\
\hline
\end{tabular}

Tabel 3. menunjukkan nilai cross loading masing-masing indikator yang diteliti pada penelitian ini. Nilai cross loading masing-masing indikator menunjukan nilai yang lebih tinggi daripada nilai cross loadings indikator tersebut dalam konstruk lainnya. Maka kriteria dari discriminant validity dengan pendekatan nilai cross loading terpenuhi. Tabel 4. menunjukan hasil analisis nilai Fornell-Larcker dari setiap variabel yang akan disajikan di bawah ini.

Tabel 4. Hasil Analisis Fornell-Larcker

\begin{tabular}{|l|l|l|l|l|}
\hline & $\begin{array}{l}\text { Financial } \\
\text { Behavior }\end{array}$ & $\begin{array}{l}\text { Financial } \\
\text { Satisfaction }\end{array}$ & $\begin{array}{l}\text { Financial } \\
\text { Strain }\end{array}$ & $\begin{array}{l}\text { Risk } \\
\text { Tolerance }\end{array}$ \\
\hline Financial Behavior & 0.743 & & & \\
\hline Financial Satisfaction & 0.179 & 0.787 & & \\
\hline Financial Strain & -0.139 & -0.213 & 0.856 & \\
\hline Risk Tolerance & -0.146 & -0.596 & 0.268 & 0.722 \\
\hline
\end{tabular}

Tabel 4. menunjukkan nilai akar kuadrat AVE setiap variabel yang diteliti lebih besar dari korelasi antar variabel. Hasil tersebut menunjukan bahwa kriteria dari analisis fornell-larcker pada discriminant validity terpenuhi.

Suatu instrumen dinyatakan reliabel jika instrumen tersebut memiliki nilai Cronbach's alpha dan composite-reliability untuk tiap variabel lebih besar dari 0,6. Cronbach's alpha dan composite-reliability pada variabel yang diteliti akan disajikan pada tabel 5 . di bawah ini:

Tabel 5 . Hasil analisis reliabilitas

\begin{tabular}{|l|c|c|}
\hline & Cronbach's Alpha & $\begin{array}{l}\text { Composite } \\
\text { Reliability }\end{array}$ \\
\hline Financial Behavior & 0.805 & 0.860 \\
\hline
\end{tabular}




\begin{tabular}{|l|c|c|}
\hline Financial Satisfaction & 0.877 & 0.907 \\
\hline Financial Strain & 0.922 & 0.932 \\
\hline Risk Tolerance & 0.816 & 0.866 \\
\hline
\end{tabular}

Tabel 5. di atas menunjukan nilai cronbach's alpha dan composite reliability masingmasing variabel yang diteliti memiliki nilai lebih besar dari 0,6. Maka variabel-variabel yang diteliti pada penelitian ini dapat dinyatakan reliabel.

Koefisien determinasi adalah ukuran dari akurasi prediksi sebuah model. Koefisien determinasi mewakili efek gabungan variabel eksogen pada variabel endogen, dengan kata lain koefisien determinasi bertujuan untuk melihat kontribusi variabel eksogen untuk memprediksi variabel endogen. Hasil koefisien determinasi akan ditampilkan pada tabel 6 .

berikut ini.

Tabel 6. Hasil Pengujian Koefisien Determinasi $\left(\mathrm{R}^{2}\right)$

\begin{tabular}{|c|c|}
\hline Variabel & R Square \\
\hline Financial Satisfaction & 0.366 \\
\hline
\end{tabular}

hasil pengujian koefisien determinasi $\left(\mathrm{R}^{2}\right)$ adalah sebesar 0,366 yang dapat diartikan bahwa $36,6 \%$ dari variabel dependen dalam penelitian ini yaitu financial satisfaction dapat dijelaskan oleh variabel independent (financial behavior, risk tolerance dan financial strain), sisanya sebesar 63,4\% dijelaskan oleh variabel-variabel di luar dari penelitian ini. Nilai koefisien determinasi yang diperoleh dalam penelitian ini tergolong lemah.

Tabel 7. Hasil Bootstrapping

\begin{tabular}{|c|c|c|c|}
\hline & Path Cofficients & t-statistics & $p$-values \\
\hline Financial Behavior -> Financial Satisfaction & 0.089 & 1.130 & 0.184 \\
\hline Risk Tolerance -> Financial Satisfaction & -0.570 & 9.075 & 0.000 \\
\hline Financial Strain -> Financial Satisfaction & -0.048 & 0.683 & 0.495 \\
\hline
\end{tabular}

Berdasarkan tabel 7 dapat disimpulkan persamaan dalam penelitian ini adalah $\mathrm{FS}=$ 0,089FB -0,570RT -0,048FSN. Nilai path coefficient menunjukan bahwa nilai prediksi variabel financial behavior terhadap financial satisfaction mempunyai arah yang positif sebesar 0,089; nilai prediksi variabel financial strain terhadap financial satisfaction mempuyai arah yang negatif sebesar 0,048 ; serta nilai prediksi variabel risk tolerance terhadap financial satisfaction mempunyai arah yang negatif sebesar 0,570.

\section{pengujian hipotesis}

Berdasarkan tabel 7, dapat dilihat bahwa nilai $p$-value variabel financial behavior terhadap financial satisfaction adalah 0,184 dimana nilai ini lebih besar dari cut off value 
yaitu 0,05 , sedangkan nilai $t$-statistic nya adalah 1,330 dimana nilai ini lebih kecil dari cut off value 1,96. Sehingga dapat disimpulkan bahwa tidak terdapat pengaruh antara financial behavior terhadap financial satisfaction.

Berdasarkan tabel 7, dapat dilihat bahwa nilai p-value variabel risk tolerance terhadap financial satisfaction adalah 0,000, dimana nilai ini lebih kecil dari cut off value yaitu 0,05 , sedangkan nilai $t$-statistic nya adalah 9,075 dimana nilai ini lebih besar dari cut off value 1,96. Sehingga dapat disimpulkan bahwa terdapat pengaruh antara risk tolerance terhadap financial satisfaction.

Berdasarkan dari tabel 7, dapat dilihat bahwa nilai p-value variabel financial strain terhadap financial satisfaction adalah 0,495 dimana nilai ini lebih besar dari cut off value yaitu 0,05 , sedangkan nilai $t$-statistic nya adalah 0,683 dimana nilai ini lebih kecil dari cut off value 1,96. Sehingga dapat disimpulkan bahwa tidak terdapat pengaruh antara financial strain terhadap financial satisfaction.

\section{DISKUSI}

\section{Pengaruh Financial Behavior terhadap Financial Satisfaction}

Hasil dari penelitian ini menunjukan bahwa financial behavior tidak berpengaruh terhadap financial satisfaction. Berdasarkan tabel 4.13, dapat dilihat bahwa nilai $p$-value variabel financial behavior terhadap financial satisfaction adalah 0,184 dimana nilai ini lebih besar dari cut off value yaitu 0,05 , sedangkan nilai $t$-statistic nya adalah 1,330 dimana nilai ini lebih kecil dari cut off value 1,96 yang berarti bahwa H1 ditolak.

Variabel financial behavior terhadap financial satisfaction mempunyai arah yang positif maksudnya adalah individu yang menerapkan perilaku keuangan dengan baik maka seharusnya akan semakin besar pula tingkat financial satisfaction.

Dalam penelitian ini, banyak responden yang menjawab netral atas pernyataanpernyataan dalam kuesioner untuk financial behavior. hal ini diduga karena responden masih ragu-ragu atas pernyataan-pernyataan tersebut sehingga diduga responden masih kurang menerapkan financial behavior sehingga tidak berpengaruh terhadap financial satisfaction.

\section{Pengaruh Risk Tolerance terhadap Financial Satisfaction}

Hasil dari penelitian ini menunjukan bahwa risk tolerance berpengaruh terhadap financial satisfaction. Berdasarkan tabel 4.13, dapat dilihat bahwa p-value variabel risk tolerance terhadap financial satisfaction adalah 0,000 dimana nilai ini lebih kecil dari cut off value yaitu 0,05 , sedangkan nilai $t$-statistic nya adalah 9,075 dimana nilai ini lebih besar dari cut off value 1,96. Sehingga dapat disimpulkan bahwa terdapat pengaruh risk tolerance terhadap financial satisfaction. Pada risk tolerance, indikator yang paling berpengaruh pada financial satisfaction adalah indikator dengan pernyataan bahwa mendapatkan uang dari saham dan obligasi adalah berdasarkan keberuntungan

Hasil penelitian ini sesuai dengan penelitian-penelitian sebelumnya yang dilakukan oleh 
Jeong dan Hanna (2004) yang menyatakan bahwa terdapat pengaruh risk tolerance terhadap financial satisfaction; Joo dan Grable (2004); Halim dan Astuti (2015); Woodyard dan Rob (2015) juga menyatakan bahwa terdapat pengaruh risk tolerance terhadap financial satisfaction.

\section{Pengaruh Financial Strain terhadap Financial Satisfaction}

Hasil dari penelitian ini menunjukan bahwa financial strain tidak berpengaruh terhadap financial satisfaction. Berdasarkan dari tabel 4.13, dapat dilihat bahwa $p$-value variabel financial strain terhadap financial satisfaction adalah 0,495 dimana nilai ini lebih besar dari cut off value sebesar 0,05 , sedangkan nilai $t$-statistic nya adalah 0,683 dimana nilai ini lebih kecil dari cut off value sebesar 1,96. Sehingga dapat disimpulkan bahwa tidak terdapat pengaruh financial strain terhadap financial satisfaction.

Hasil penelitian ini berhubungan jawaban responden. Mayoritas jawaban responden atas pernyataan pada kuesioner variabel financial strain adalah sangat tidak setuju, hal ini diduga karena responden tidak merasakan financial strain sehingga tidak mempengaruhi financial satisfaction.

\section{Saran}

Berdasarkan hasil penelitian yang diperoleh, maka beberapa saran yang dapat

1. Pada penelitian selanjutnya, diharapkan agar wilayah untuk pengambilan sampel penelitian dapat diperluas, mencakup kota yang lain bukan hanya di wilayah Jakarta saja.

2. Pada penelitian selanjutnya, diharapkan agar dapat menambah jumlah responden yang dijadikan sebagai sampel penelitian agar hasil penelitian yang diperoleh dapat lebih akurat.

3. Pada penelitian selanjutnya, peneliti dapat mencoba menggunakan responden dengan profesi yang berbeda.

4. Pada penelitian selanjutnya, disarankan untuk menambahkan variabel-variabel independen lainnya yang diduga dapat mempengaruhi financial satisfaction seperti financial stress, financial stressor, dan perceived financial capability.

5. Bagi pemerintah, disarankan untuk lebih memperhatikan kesejahteraan para dokter, khususnya para dokter yang masih muda karena dari hasil penelitian ini, diketahui bahwa masih ada dokter yang mempunyai pendapatan per bulan kurang dari Rp5.000.000,-

\section{DAFTAR PUSTAKA}

Aboagye, Ji (2018). Debt Holding, Financial Behavior, and Financial satisfaction. Journal of Financial Counseling and Planning Education, 29(2), 208-218.

Altsani, Hasibuan, Lubis (2017). Financial Literacy and Financial Behavior as a Measure of Financial Satisfaction. Atlantis Press, 46. 503-507

Arifin, A. Z. (2018). Influence Factors toward Financial Satisfaction with Financial Behavior as Intervening Variable on Jakarta Area Workforce. European Research Studies Journal, 21(1), 90-103

Bagozzi, R. P., \& Yi, Y. (1988). On the Evaluation of Structural Equation Models. Journal of the Academy of Marketing Science, 16(1), 74-94. doi:10.1177/009207038801600107 Coşkuner, S. (2016). Understanding Factors 
Affecting Financial Satisfaction: The Influence of Financial Behavior, Financial Knowledge and Demographics. Imperial Journal of Interdisciplinary Research (IJIR), 2(5), 377-385.

Falahati, L., Sabri, M. F., \& Paim, L. (2012). Assessment a Model of Financial Satisfaction Predictors: Examining the Mediate Effect of Financial Behaviour and Financial Strain. World Applied Sciences Journal, 20(2), 190-197.

Grable, J. E. \& Lytton, R. H. 1998. Investor Risk Tolerance: Testing the Efficacy of Demographics as Differentiating and Classifiying Factors. Financial Counceling and Planning.

Halim, Y. K., \& Astuti, D. (2015). Financial Stressors, Financial Behavior, Risk Tolerance, Financial Solvency, Financial Knowledge, dan Kepuasan Finansial. FINESTA, 3(1), 19-23.

Jeong, Hanna (2004). Risk Tolerance and Financial Satisfaction. International Journal of Human Ecology, 5, 35-43

Joo, S., \& Grable, J. E. (2004). An Exploratory Framework of the Determinants of Financial Satisfaction. Journal of Family and Economic Issues, 25(1), 25-50. doi:10.1023/b:jeei.0000016722.37994.9f

Kirbiš, I. Š., Vehovec, M., \& Galić, Z. (2016). Relationship between Financial Satisfaction and Financial Literacy: Exploring Gender Differences. Drustvena istrazivanja, 26(2), 165-185. doi:10.5559/di.26.2.02

Malhotra, N. K. (2010). Marketing research: An applied approach. Boston: Pearson._ (2015). Essentials of Marketing Research, Global Edition.

Selligman, Martin E. P. (2002). Authentic Happiness: Using The New Positive Psychology To Realize Your Potential For lasting Fulfillment. Bandung: PT. Mizan Pustaka

Woodyard, A. S., \& Robb, C. A. (2016). Consideration of Financial Satisfaction: What Consumers Know, Feel and Do from a Financial Perspective. Journal of Financial Therapy, 7(2). doi:10.4148/1944-9771.1102

Yap, R. J., Komalasari, F., \& Hadiansah, I. (2016). The Effect of Financial Literacy and Attitude on Financial Management Behavior and Satisfaction. International Journal of Administrative Science \& Organization, 23(3). doi:10.20476/jbb.v23i3.9175 